\title{
Safety and Outcome of Outpatient 2-Level Hybrid Anterior Cervical Discectomy and Fusion plus Adjacent Total Disc Replacement \\ KR Chin ${ }^{1,2,3}$, FJR Pencle ${ }^{4}$, AV Coombs ${ }^{4}$, JA Seale ${ }^{3}$
}

\begin{abstract}
Objective: The emergence of modern technologies and surgical techniques has challenged anterior cervical discectomy and fusion $(A C D F)$ as the gold-standard treatment for cervical spondylosis. In an effort to reduce fusion levels and preserve mobility, combining ACDF and total disc replacement $(T D R)$ has been explored in the literature. No reports were found which investigated the feasibility of this hybrid procedure in an ambulatory surgery centre (ASC). The authors aim to determine the feasibility of performing combined ACDF with TDR in an ASC.

Methods: We evaluated medical records of 15 consecutive patients, who presented with multilevel cervical degenerative disc disease. Single-stage instrumented ACDF with concurrent cervical TDR was performed in an ASC. Outcome measures examined were visual analogue scale (VAS) scores for neck pain, neck disability index (NDI), nurick grade, quality of life assessment (QoL) through the physical and mental composite scores (PCS and MCS) of the Short-Form 12 (SF-12) health survey and complications. Outpatient spine surgery protocols and guidelines are provided.

Results: Males accounted for $70 \%$ of the patient population with overall mean age of $45.13 \pm 1.9$ years with mean body mass index (BMI) of $28.2 \pm 8.5 \mathrm{~kg} / \mathrm{m}^{2}$. Minimum follow-up was 12 months. Estimated blood loss was $71 \pm 23$ milliliters and mean operating time was 45 minutes. Clinically significant improvement was achieved in $80 \%$ of patients with mean VAS score for neck pain of 8.4 \pm 0.8 reducing to $4.5 \pm 1.2$, which was statistically significant $(\mathrm{p}=0.043)$. Similarly, pre-operative mean NDI of $55 \pm 7 \%$ reduced to $33 \pm 9 \%$ postoperatively $(\mathrm{p}=0.03)$. Nurick grades were 0 in each patient by final follow-up and there were no complications reported. Overall improvement in $Q o L$ was also accomplished.

Conclusion: Combined ACDF and TDR can be safely done in an ASC with satisfactory clinical and patient-reported outcomes.
\end{abstract}

Keywords: Ambulatory surgery centre, anterior cervical discectomy and fusion, cervical spondylosis, hybrid surgery, outcomes, outpatient, total disc replacement

\section{Seguridad y resultado de la discectomía y fusión cervical anterior híbrida de dos niveles ambulatoria con reemplazo total del disco adyacente}

KR Chin ${ }^{1,2,3}$, FJR Pencle ${ }^{4}$, AV Coombs ${ }^{4}$, JA Seale ${ }^{3}$

\begin{abstract}
RESUMEN
Objetivo: La aparición de modernas tecnologías y técnicas quirúrgicas ha desafiado la discectomía y fusión cervical anterior (DFCA) como el tratamiento de referencia para la espondilosis cervical. En un esfuerzo por reducir los niveles de fusión y preservar movilidad, se explora la literatura en busca de la combinación de DFCA y el reemplazo total de disco (RTD). No se han encontrado reportes de investigación de la viabilidad de este procedimiento híbrido en centros de cirugía ambulatoria (CCA). Los autores tienen por objetivo determinar la viabilidad de realizar la combinación de DFCA con el RTD en un CCA.

Métodos: Se evaluaron las historias clínicas de 15 pacientes consecutivos, que se presentaron con enfermedad degenerativa multinivel del disco cervical. Una DFCA instrumentada en una sola etapa
\end{abstract}

From: ${ }^{1}$ Charles E. Schmidt College of Medicine at Florida Atlantic University, USA, ${ }^{2}$ Herbert Wertheim College of Medicine at Florida International University, USA, ${ }^{3}$ Less Exposure Surgery Specialists Institute (LESS Institute), USA and ${ }^{4}$ Less Exposure Surgery (LES) Society, USA.
Correspondence: Dr K Chin, Less Exposure Surgery Specialists Institute (LESS Institute), 1100 W. Oakland Park Blvd. Suite \#3, Fort Lauderdale, FL, 33311, USA. Email: kingsleychin@theless institute. com 
con RTD concurrente fue realizada en un CCA. Las mediciones de los resultados evaluadas fueron: las puntuaciones de la Escala visual analógica (EVA) para el dolor de cuello, el Índice de discapacidad cervical (IDC), el grado en la Escala de Nurick, la evaluación de la Escala de calidad de vida $(E C V)$ a través de las puntuaciones compuestas del sumario del componente fisico y el mental (SCF y SCM) del Cuestionario de salud general SF-12, y las complicaciones. Se proporcionan directrices y protocolos para la cirugía de columna ambulatoria.

Resultados: Los varones representaron el 70\% de la población de pacientes con una edad media general de $45.13 \pm 1.9$ años. Su indice de masa corporal promedio (IMC) fue $28.2 \pm 8.5 \mathrm{~kg} / \mathrm{m}^{2}$. El seguimiento mínimo fue de 12 meses. La pérdida de sangre estimada fue de $71 \pm 23$ mililitros, y el tiempo de operación promedio fue de 45 minutos. Se logró una mejoría clínicamente importante en el $80 \%$ de los pacientes, al reducirse la puntuación promedio del dolor cervical según EVA, de 8.4 \pm 0.8 a $4.5 \pm 1.2$, de manera estadisticamente significativa $(\mathrm{p}=0.043)$. De modo similar, el indice de discapacidad cervical (IDC) preoperatorio promedio, se redujo de $55 \pm 7 \%$ a $33 \pm 9 \%$ postoperatoriamente $(\mathrm{p}=0.03)$. Los grados de Nurick fueron 0 en cada paciente en el seguimiento final, y no se reportaron complicaciones. En general también se logró mejoría en la ECV.

Conclusión: La DFCA y el TDR pueden combinarse de forma segura en un CCA con resultados clínicos y reportes satisfactorios de los pacientes.

Palabras claves: Centro de cirugía ambulatoria, discectomía y fusión cervical anterior, espondilosis cervical, cirugía híbrida, resultados, ambulatorio, reemplazo total de disco

West Indian Med J 2016; 66 (3): 441

\section{INTRODUCTION}

The dominance of anterior cervical discectomy and fusion (ACDF) as the "gold standard" treatment for cervical spondylosis for many years is being challenged by emerging technologies and novel techniques available to spine surgeons. Concerns over the risk of adjacent segment disease (ASD), increase incidence of dysphagia and the desire for less invasive surgery with faster recovery has fueled the development of cervical arthroplasty as a viable alternative particularly with multilevel fusions (1-3). Cervical total disc replacement (TDR) attempts to treat radicular pain and simultaneously preserve functional motion in patients suffering from spondylotic degeneration. Results from a prospective, randomized, controlled multicentre FDA trial concluded that when compared with clinical outcomes, the benefits of cervical TDR were either equivalent, or superior to those after ACDF (4).

The feasibility of performing both ACDF and cervical TDR in a single patient has been demonstrated in a hospital setting $(5,6)$. The purpose of this paper is to present mid-term follow-up results for patients having a single-stage, combined instrumented ACDF and cervical TDR in an ambulatory surgery centre (ASC) with recommended outpatient guidelines based on our ongoing experience.

\section{SUBJECTS AND METHODS}

The medical records of 15 consecutive patients, who presented with multilevel cervical degenerative disc disease (DDD) resulting in myelopathy with or without radiculopathy, were reviewed (Fig. 1).

Patients were only considered for surgery after failed conservative management for at least six weeks, which included anti-inflammatory medication, physical therapy and epidural

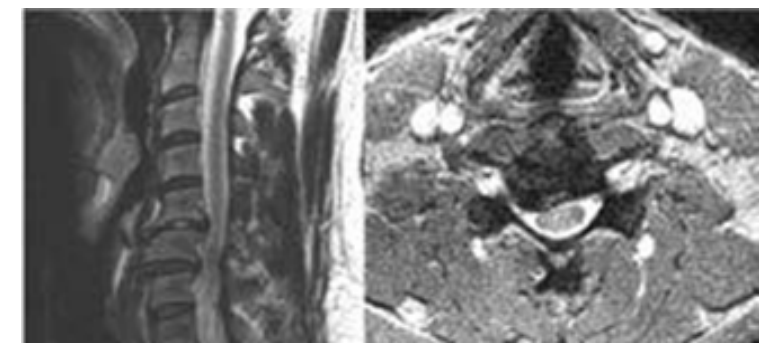

Fig. 1: Sagittal and axial views of a pre-operative magnetic resonance imaging showing multilevel disease worse at C5-6 and C6-7. Axial cut is taken at C5-6 showing a right paracentral disc herniation with compression.

steroid injections. Pre-operative clinical assessment was made with a comprehensive history and physical examination and the use of the nurick and neck disability index (NDI) grading systems along with appropriate anteroposterior (AP), lateral radiographs and magnetic resonance imaging (MRI).

Patients with chronic medical conditions were stable and cleared by their physician and/or cardiologist in the case of cardiac disease, prior to surgery. Indications for TDR, included symptomatic spontaneous/degenerative or traumatic herniated cervical nuclei pulposus with or without radiculopathy and cervical degenerative disc degeneration (DDD) without posterior column instability. Indications for ACDF included cervical spondylosis, stenosing herniated discs, degenerative disc disease with instability and facet arthritis, tropism or facetogenic pain. Exclusion criteria for outpatient surgery included, acute severe trauma, fractures, malignancy, infection, unstable chronic medical illnesses, prior anterior cervical fusions or total disc arthroplasty and BMI $>42(7,8)$. The eligibility criteria for surgical intervention for outpatient spine candidates was based on previous study (8).

Informed consent regarding the procedure and its rationale 
was obtained and patients were also made aware that based on intra-operative findings, the proposed surgical procedure could change. Patients were mobilized within hours of surgery and an experienced registered nurse and the attending anaesthesiologist confirmed that patients were fully oriented. All patients were discharged with a responsible adult to drive them home only after confirmation that they were neurologically intact by the attending spine surgeon. Established transfer agreements between the ASC and with neighbouring hospitals within 30 minutes, ensured a mechanism for hospital admission if patients developed any serious problems. cardiac arrest.

\section{Follow-up}

- Patients were instructed on standardized postoperative protocol (Fig. 2).

- $\quad$ Patients were called the night of surgery, after discharge and again the morning after surgery.

- The first clinic follow-up visit was at one to two weeks postoperatively and physical therapy was started. Follow-up continued at six weeks; three, six and twelvemonth follow-up thereafter.

All patients had AP and lateral radiographs within the first two weeks postoperatively to ensure implant compliance, and at twelve months to assess for fusion. Functional outcome was assessed by comparison of pre-operative and postopera-tive patient numeric rating scale/VAS for neck pain as well as the Nurick grade, NDI and quality of life assessment (QoL) through the physical and mental composite scores (PCS and MCS) of the Short-Form 12 (SF-12) health survey.

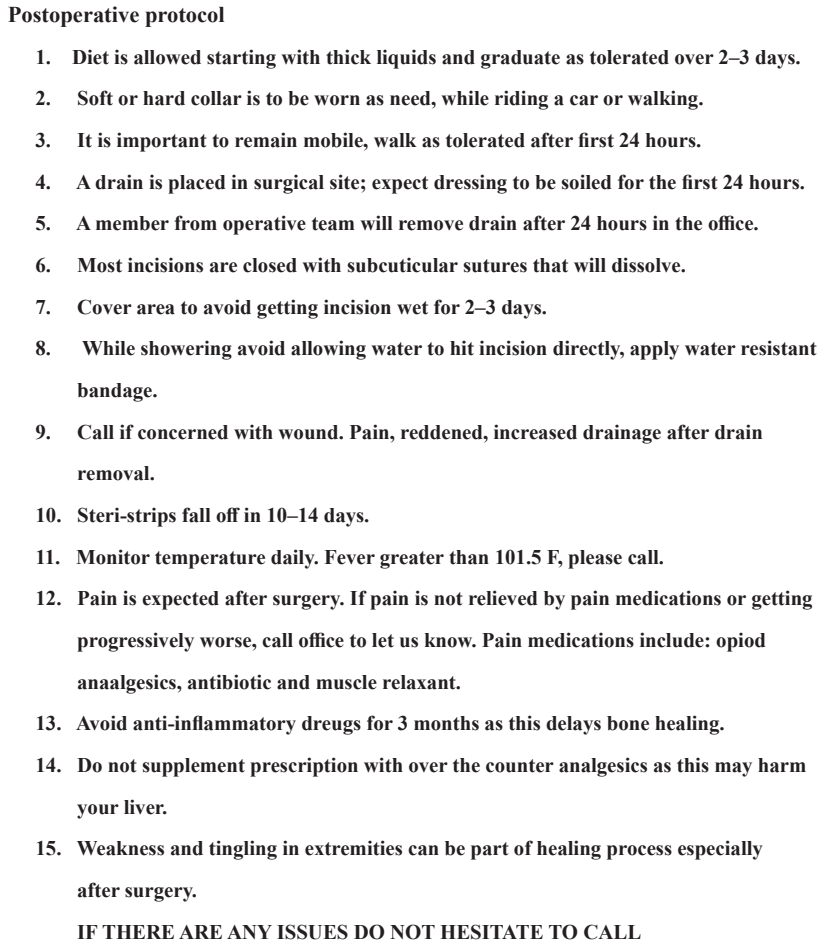

Fig. 2: Postoperative protocol, which was explained and given to all patients and their caregivers prior to discharge from the ambulatory surgery centre.

\section{Surgical technique}

Signed consent was obtained for the procedure and under general anaesthesia; patients were prepped and draped under sterile conditions. A modified approach to the standard SmithRobinson operative technique was used (9). Surgical exposure of the desired vertebral level was achieved through a transverse midline anterior cervical incision. Following discectomy with pituitary ronguers, curette and burr drill to remove affected disc, the posterior longitudinal ligament was retained in situ (10). The centre of the disc was identified to begin trialing. A keel was made using burr after which trial was removed and disc arthroplasty performed with Prodisc-C ${ }^{\circledR}$, Synthes Inc, and West Chester, PA, USA). Discectomy was repeated at the other affected level. Appropriately sized PEEK interbody cage (Arena-C ${ }^{\circledR}$, SpineFrontier Inc, Malden, MA, USA) packed with DBM pure placed and fusion aided with anterior cervical plate (ACP) (Inset ${ }^{\circledR}$, SpineFrontier Inc, Mal-den, MA, USA).

Once haemostasis was achieved and the wound was completely dry (Fig. 3), a Penrose drain was placed above the implants and brought though the incision and secured with a sterile safety pin in outpatients for wound drainage to prevent postoperative haematoma development at home. Statistical analysis was performed using Microsoft Excel version 14.1.3. Comparisons were expressed as counts or means with standard error. Tests were considered significant if $p<0.05$.

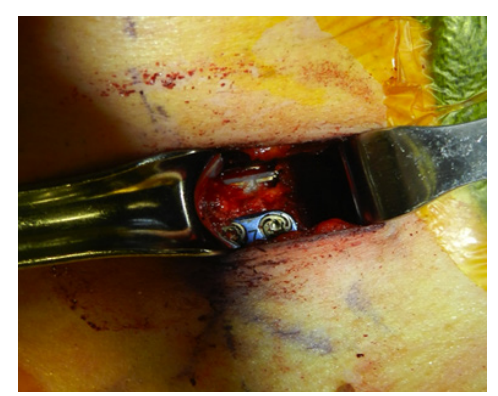

Fig. 3: Intra-operative photograph showing an artificial disc above an adjacent anterior cervical plate.

\section{RESULTS}

Mean age was $45.13 \pm 1.9$ years, with males accounting for $70 \%$ of the patient population. Minimum follow-up was seven months with a mean of $19.34 \pm 6.34$ months. Mean BMI was $28.2 \pm 8.5 \mathrm{~kg} / \mathrm{m}^{2}$. History of smoking and narcotics use was statistically non-contributory. Estimated blood loss was $71 \pm 23$ millilitres and mean operating time was 45 minutes. Clinically significant improvement was achieved in $80 \%$ of patients with mean VAS score for neck pain of $8.4 \pm 0.8$ reducing to $4.5 \pm 1.2$, which was statistically significant $[p=0.043]$ (Fig. 5).

Similarly, pre-operative mean NDI of $55 \pm 7 \%$ reduced to $33 \pm 9 \%$ postoperatively $[p=0.03$ ] (Fig. 6).

Nurick grades were 0 in each patient by final follow-up and there were no complications reported. Quality of life assessment through SF-12 interpretation revealed that a minimum clinically important improvement was achieved: mean 
pre-operative PCS $35.9 \pm 3.9$, MCS $45.5 \pm 3.2$ improved to mean postoperative PCS $40.5 \pm 3.3$, MCS $45.9 \pm 3.5$. Although improvements in QoL were observed, these changes were not statistically significant $(p=0.41$ for PCS and $p=$ 0.93 for MCS). Fusion was demonstrated at 12 months follow-up (Fig. 4) at the level where ACDF was performed.

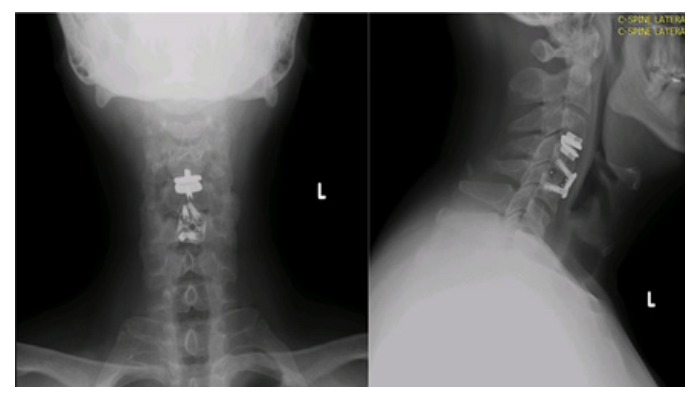

Fig. 4: Postoperative anteroposterior and lateral radiographs showing total disc replacement in satisfactory position at $\mathrm{C} 3-4$ and an interbody fusion device at the level of C4-5 where anterior cervical discectomy and fusion was performed.

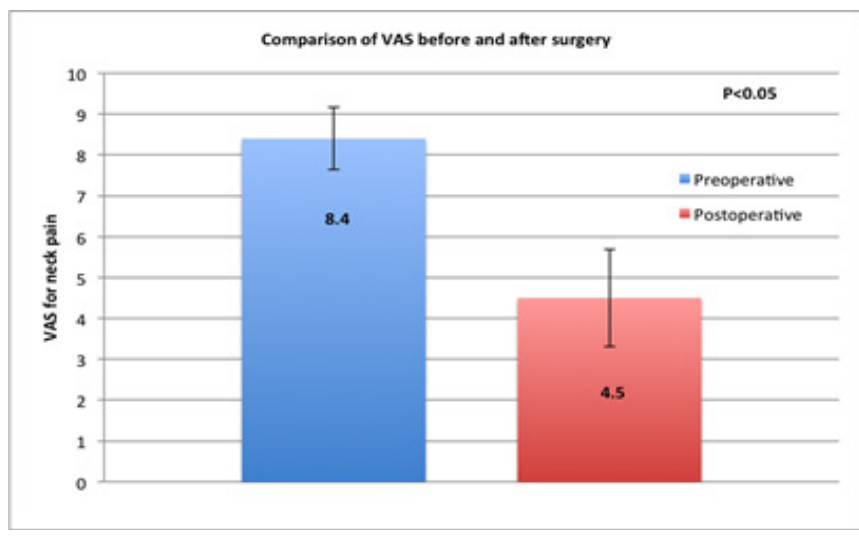

Fig. 5: Chart showing the comparison between pre-operative and postoperative visual analogue scale scores for neck pain.

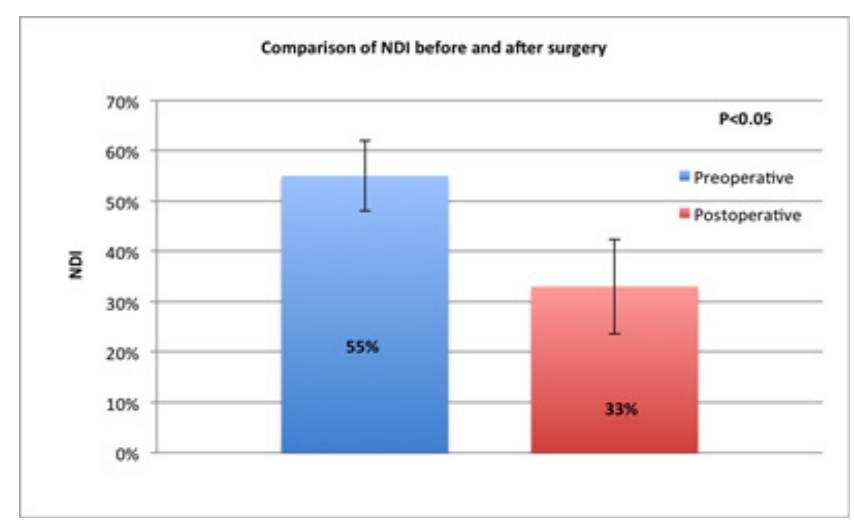

Fig. 6: Chart showing the comparison between pre-operative and postoperative neck disability index scores for neck pain.

\section{DISCUSSION}

Cervical spondylosis is a common disease of the cervical spine, particularly in older adults, as a consequence of ageing (11). Treatment is initiated with conservative measures for at least six months prior to surgical intervention, which can be broadly classified into fusion and non-fusion techniques (12). Although both techniques have many described advantages and disadvantages (13), ACDF has traditionally been the most common surgical treatment method described, especially since the emergence of ACPs, which have been shown to enhance fusion rates (14).

A commonly expressed concern within the literature is that of the influence of ACPs on the development of ASD and moderate to severe dysphagia following ACDF $(15,16)$. Several studies have shown that this risk increases with the more levels fused though class one evidence is yet to be established (17). Concerns over these complications and the uncertain sequelae of ACDF lead to the development of total (or artifi-cial) disc replacement as a feasible alternative (12).

Biomechanical and clinical studies comparing the two procedures have suggested that increased intradiscal pressures and shear forces at the adjacent levels contribute to accelerated degeneration following fusions with ACP whereas physiologic cervical motion can be preserved with TDR, unlike $\operatorname{ACDF}(15,18,19)$. Currently, there exists no clear evidence for the superiority of one procedure over the other, however, one major advantage of using TDR over a fusion for less severely degenerated segments is a young and active patient with a high life expectancy (13).

The rationale for the use of this combined fusion-nonfusion technique to treat these patients was based on numerous factors. Varying stages of degeneration exist in patients with spondylotic disease at multiple levels hence, we felt it prudent to limit the extent of surgery by fusing only the segment with the most degenerative changes or patients with facet-mediated pain. Degenerative changes were evidenced by pain and limited segmental motion on physical examination and pre-operative radiologic evidence of partial fusion or osteophytes intimately involved with the facet joints, facet reactive changes or hypertrophy. A TDR in the case of facet pathology will not address the patient's pain and should be rendered futile.

Secondly, we felt that younger and middle-aged patients were more likely to benefit due, to the likelihood of development of adjacent segment disease over-time, with a higher life expectancy, in addition to the motion sparing benefit of a TDR in terms of quality of life with less levels fused. Although desirable, two level cervical TDR has been studied and reported but is not currently FDA-approved in the cervical spine (20). Older patients would also benefit due to a less morbid procedure such as a three-level ACDF. Furthermore, upper cervical levels are more challenging to access surgically, especially with an ACP due to more complex anatomy and less mobile upper oesophagus. Thus, in order to limit prolonged surgery and increased complication risks, we chose TDR for higher diseased cervical levels, which were less severe and did not warrant full fusion. The risk of postoperative dysphagia has been shown to be increased after ACDF as well as with the more cervical levels fused $(16,21)$, hence, our preference to 
use a TDR in the superior less degenerated segments. Finally, with more recent evidence revealing mid and long-term follow-up data showing that the incidence of ASD is not increased after TDR (12), we were encouraged to offer this to our patients at levels where we believed surgical intervention was warranted but ACDF was too aggressive.

Midterm follow-up revealed that patient-reported outcomes were excellent with this combined fusion-non-fusion technique in an ASC. Statistically significant improvement was achieved in reducing pain and disability as evidenced by the mean postoperative Nurick grades and NDI scores.

Recently, authors have begun looking at the feasibility of combining ACDF with TDR for a variety of indications $(5,6)$. We found one study in the literature that reported the suc-cess of a single-stage "hybrid fusion-non-fusion procedure" as described, which was almost identical to our study (5). However, this was a hospital-based study with slightly differ-ent eligibility criteria and did not utilize ACP as part of their fusion technique.

To our knowledge, this is the first paper, which reports on the outcomes of these cases being done in a single operation, in an outpatient setting. Further, long-term follow-up studies are warranted to conclude whether this procedure does, in fact, reduce the incidence of adjacent segment disease. Additionally, whether this combined technique may lead to biomechanical compromise of the artificial disc adjacent to a fused segment is yet to be determined, however, based on a recent biomechanical study (22) and our clinical experience thus far, this has not been shown to occur. We have had no cases of hardware failure as a direct or indirect consequence of this combined technique to date. Limitations of this study acknowledged are its retrospective nature and small sample size with no control group. This paper adds to the body of knowledge on outpatient spine surgery and the use of a hybrid technique in patients with multilevel disease.

\section{CONCLUSION}

Through a consistent operating team and strict follow-up protocols, we were able to achieve satisfactory midterm clinical and radiologic results after combining instrumented ACDF with cervical TDR for the treatment of multilevel cervical spondylosis in an ambulatory surgery centre.

\section{AUTHORS' NOTES}

Conflicts of interest and sources of funding: We did not seek or receive any funding from the National Institutes of Health (NIH), Wellcome Trust, Howard Hughes Medical Institute (HHMI), or others for this work. Dr KR Chin is a shareholder in and receives other benefits from SpineFrontier Inc., neither of the other two authors (AVC, FJRP, JAS) have any potential conflicts of interest to declare for this work

\section{REFERENCES}

1. Garrido BJ, Wilhite J, Nakano M, Crawford C, Baldus C, Riew KD et al. Adjacent-level cervical ossification after Bryan cervical disc arthroplasty compared with anterior cervical discectomy and fusion. J Bone Joint Surg Am 2011; 93: 1185-9.
2. Tortolani PJ, Cunningham BW, Vigna F, Hu N, Zorn CM, McAfee PC. A comparison of retraction pressure during anterior cervical plate surgery and cervical disc replacement: a cadaveric study. J Spinal Disord Tech 2006; 19: 312-7.

3. Riley LH, 3rd, Skolasky RL, Albert TJ, Vaccaro AR, Heller JG. Dysphagia after anterior cervical decompression and fusion: prevalence and risk factors from a longitudinal cohort study. Spine 2005; 30: 2564-9.

4. Murrey D, Janssen M, Delamarter R, Goldstein J, Zigler J, Tay B et al. Results of the prospective, randomized, controlled multicentre Food and Drug Administration investigational device exemption study of the ProDisc-C total disc replacement versus anterior discectomy and fusion for the treatment of 1-level symptomatic cervical disc disease. Spine J 2009; 9: $275-86$

5. Barbagallo GM, Assietti R, Corbino L, Olindo G, Foti PV, Russo V et al. Early results and review of the literature of a novel hybrid surgical technique combining cervical arthrodesis and disc arthroplasty for treating multilevel degenerative disc disease: opposite or complementary techniques? Eur Spine J 2009; 18 (Suppl 1): 29-39.

6. Lee SB, Cho KS, Kim JY, Yoo DS, Lee TG, Huh PW. Hybrid surgery of multilevel cervical degenerative disc disease: review of literature and clinical results. J Korean Neurosurg Soc 2012; 52: 452-8.

7. Chin KR, Coombs AV, Seale JA. Feasibility and patient-reported outcomes after outpatient single-level instrumented posterior lumbar interbody fusion in a surgery centre: preliminary results in 16 patients. Spine 2015; 40: E36-42.

8. Chin KR, Pencle FJ, Coombs AV, Packer CF, Hothem EA, Seale JA. Eligibility of outpatient spine surgery candidates in a single private practice. Clin Spine Surg 2017; 30: E1352-8.

Robinson RA, Smith GW. Anterolateral cervical disc removal and inter-

9. body fusion for cervical disc syndrome. Bull John Hopkins Hosp 1955; 96 SRC - GoogleScholar: 223-4.

Chin KR, Ghiselli G, Cumming V, Furey CG, Yoo JU, Emery SE. Post-

10. operative magnetic resonance imaging assessment for potential compressive effects of retained posterior longitudinal ligament after anterior cervical fusions: a cross-sectional study. Spine 2013; 38: 253-6.

11. Lestini WF, Wiesel SW. The pathogenesis of cervical spondylosis. Clin Orthop Relat Res 1989; 239: 69-93.

12. Cho SK, Riew KD. Adjacent segment disease following cervical spine surgery. J Am Acad Orthop Surg 2013; 21: 3-11.

13. Moatz B, Tortolani PJ. Cervical disc arthroplasty: pros and cons. Surg Neurol Int 2012; 3(Suppl 3): S216-24.

14. Agrillo U, Faccioli F, Fachinetti P, Gambardella G, Guizzardi G, Profeta G. Guidelines for the diagnosis and management of the degenerative diseases of cervical spine. J Neurosurg Sci 1999; 43: 11-4.

15. Hilibrand AS, Carlson GD, Palumbo MA, Jones PK, Bohlman HH. Radiculopathy and myelopathy at segments adjacent to the site of a previous anterior cervical arthrodesis. J Bone Joint Surg Am 1999; 81: 519-28.

16. Cho SK, Lu Y, Lee DH. Dysphagia following anterior cervical spinal surgery: a systematic review. Bone Joint J 2013; 95: 868-73.

17. Singh K, Marquez-Lara A, Nandyala SV, Patel AA, Fineberg SJ. Incidence and risk factors for Dysphagia after anterior cervical fusion. Spine 2013; 38: 1820-5.

18. DiAngelo DJ, Foley KT. An improved biomechanical testing protocol for evaluating spinal arthroplasty and motion preservation devices in a multilevel human cadaveric cervical model. Neurosurg Focus 2004; 17: E4.

19. Robertson JT, Papadopoulos SM, Traynelis VC. Assessment of adjacent-segment disease in patients treated with cervical fusion or arthroplasty: a prospective 2-year study. J Neurosurg Spine 2005; 3: 417-23.

20. Wang Y, Zhang X, Xiao S, Lu N, Wang Z, Zhou M. Clinical report of cervical arthroplasty in management of spondylotic myelopathy in Chinese. J Orthop Surg Res 2006; 1: 13.

21. McAfee PC, Cappuccino A, Cunningham BW, Devine JG, Phillips FM, Regan JJ et al. Lower incidence of dysphagia with cervical arthroplasty compared with ACDF in a prospective randomized clinical trial. J Spinal Disord Tech 2010; 23: 1-8.

22. Lee MJ, Dumonski M, Phillips FM, Voronov LI, Renner SM, Carandang $\mathrm{G}$ et al. Disc replacement adjacent to cervical fusion: a biomechanical comparison of hybrid construct versus two-level fusion. Spine 2011; 36: $1932-9$. 